\title{
Liposomal NDDP
}

National Cancer Institute

\section{Source}

National Cancer Institute. Liposomal NDDP. NCI Thesaurus. Code C1383.

A synthetic liposomal formulation of bis-neodecanoate diaminocyclohexane platinum (NDDP), a third-generation platinum complex analogue of cisplatin, with potential antineoplastic activity. After displacement of the 2 long-chain aliphatic leaving groups (neodecanoic acid), platinum diaminocyclohexane (DACH) complexes become highly reactive and alkylate macromolecules, forming both inter- and intra-stranded DNA crosslinkings and inhibiting DNA synthesis, which results in tumor cell cytotoxicity. Because DNA mismatch-repair (MMR) complexes do not recognize DACH-platinum adducts, DNA repair mechanisms are inhibited, overcoming limitations observed with other platinumbased agents. In addition, the liposomal encapsulation improves the bioavailability of NDDP and reduces its toxicity profile. 